\title{
A Tisífone de Sílio Itálico: Púnicas 2.526-52
}

Everton da Silva Natividade

Universidade Federal de Pernambuco

Brasil

Resumo. Este artigo se concentra na primeira aparição de Tisífone no poema Púnicas de Sílio Itálico (2.526-52) e considera o retrato da divindade infernal. Inserindo Sílio no seu período de produção e analisando o excerto, delineia-se como o séquito de Tisífone, as alterações geográficas causadas pela sua presença e suas ações funcionam como instrumentos caracterizadores em tais versos, além de examinar a descrição apresentada da Eumênide, tanto nas palavras do poeta como nas de Juno. Por último, investiga-se a relação entre a Fúria e sua mandante olímpica, Juno, e argumenta-se que a Tisífone siliana é o resultado de um diálogo com a Juno virgiliana da Eneida. Palavras-Chave. Tisífone; descrição; Sílio Itálico; Juno; Eneida; Virgílio.

Sílio Itálico legou-nos apenas uma obra, um poema épico de dezessete cantos, Púnicas, cujo tema, apesar do plural do título, é apenas a Segunda Guerra Púnica. Discute-se a atribuição a ele de um poema chamado Ilias latina, a 'Ilíada latina', produção da sua juventude, um resumo da obra de Homero. Foi um homem rico e, por isso mesmo, não protegido, mas protetor: diferentemente de Estácio, por exemplo, seu contemporâneo que era um poeta cliens, Sílio Itálico era o patrono de Marcial, e este se refere ao poeta épico em vários dos seus epigramas ${ }^{1}$, sempre com muito respeito e admiração.

Sílio Itálico nasceu sob o governo de Tibério (c. 26). Sabe-se que morreu com 75 anos, depois de ter visto o filho mais velho ser honrado com o cargo de cônsul e o mais novo morrer bastante jovem. Foi um reconhecido advogado durante o governo de Cláudio (que durou de 41 a 54), delator e cônsul durante o governo de Nero (que durou de 54 a 68), procônsul na Ásia Menor, ao que parece, em 77, sob o governo de Vespasiano (que durou de 69 a 79). Como se vê, a sua vida foi testemunha do período conturbado que a dinastia júlio-claudiana implementou; da confusão que se instaurou no ano de 69, após a morte de Nero; da dinastia flaviana, um

Email: everton_natividade@yahoo.com.br

${ }^{1}$ Designadamente: 4.14, 6.64, 7.63, 8.66, 9.86, 11.48, 11.49 e 12.67. 
governo de militares. Sabe-se ainda que estava vivo quando Trajano assumiu o poder, em 98; a data aceita para a morte de Sílio Itálico é o ano de 101. A propósito do seu óbito, sabemos que morreu de inanição, tendo deixado de alimentar-se quando se descobriu portador de uma doença incurável, denominada clauus por Plínio, o Jovem ${ }^{2}$, hoje identificada com uma espécie de tumor. Interessante é o comentário de R. Marks: 'tendo vivido sob nada menos que doze imperadores e passado por um ano de sangrenta guerra civil, ele viu Roma reinventar-se muitas vezes e ainda assim perseverar'3. Essa luta de forças que a História registra, opondo tradição e inovação nos caminhos que Roma seguiu para a sua constante reinvenção, está presente no poema de Sílio Itálico, que, a partir da descrição de Tisífone, apresentada no canto II, reinventa a Fúria e a reveste da sua própria concepção imagética de poesia.

A produção das Púnicas estendeu-se provavelmente de 80 a 98, após o poeta ter-se retirado para Nápoles, onde viveu o restante da vida tranquilamente, cercado de amigos e conversas culturais nas luxuosas propriedades que colecionava. O poema, que levou quase vinte anos para ser elaborado e que se compõe de algo em torno de 12 mil versos, se inicia com a apresentação de três pontos fundamentais: as causas da guerra (1.1270); a descrição do inimigo, Aníbal, em diferentes cenas (principalmente nos seus dois retratos, $1.56-70$ e 1.239-704); e a crise de Sagunto, cidade espanhola assediada pelos cartagineses (1.271-694).

Após a Primeira Guerra Púnica, os cartagineses, uma vez perdido o controle das ilhas da Córsega, da Sardenha e da Sicília, procuraram estabelecer novos territórios de influência e, nessa empreitada, dirigiram seus esforços para o território hispânico. Traçando um caminho que ia da Nova Cartago, no sudeste da Hispânia, para o Norte, eles criavam, aos poucos, a possibilidade de movimentação que levaria Aníbal, mais tarde, a invadir a Itália, pelo Norte, atravessando os Alpes, num itinerário todo feito por terra. Mas a previsão dessa eventualidade não escapou aos olhos de Roma, que, temendo o avanço cartaginês na Hispânia, declarou guerra quando da primeira oportunidade: Sagunto ficava fora dos limites que Cartago podia transpassar, segundo um tratado que a cidade africana e Roma haviam firmado em 226 a.C. Assim, quando, em 218 a.C., Aníbal e seus homens sitiaram Sagunto, desencadeou-se a guerra.

\footnotetext{
${ }^{2}$ Ep. 3.7.

${ }^{3}$ Raymond Marks, 'Silius Italicus' in John Miles Foley (ed.), A Companion to Ancient Epic. Malden, MA; Oxford; Carlton, Blackwell Publishing, 2005, p. 536.

${ }^{4}$ Cf. Everton da Silva Natividade. Aníbal: o guerreiro cartaginês e as Púnicas de Sílio Itálico. Projeto História (São Paulo) 30, 57-69, 2005.
} 
No poema de Sílio Itálico, a cidade de Sagunto nos é apresentada no canto I, numa etiologia mitológica que liga a sua fundação ao herói-deus Hércules, num conjunto de vinte versos (1.273-93). Segundo a lenda, após tomar o rebanho de Gerião, uma criatura monstruosa que habitava a ilha de Ericia (ou Eritia ou Eriteia), próxima à costa hispânica, Hércules e seu companheiro, Zacinto, dirigiram-se para a Hispânia, onde Zacinto fundou a cidade de Sagunto, levantando-lhe a muralha com a ajuda do Alcida e atribuindo-lhe o seu nome ${ }^{5}$. Essa lenda só é narrada por Sílio Itálico, e não temos nenhum outro registro dessa etiologia ${ }^{6}$.

Após o ataque de Aníbal, os saguntinos decidem manter-se fiéis à sua aliada, Roma, e enviar embaixadores à Itália para pedir auxílio. O canto I se encerra com a decisão do Senado romano de buscar, primeiro na Hispânia e, em seguida, em Cartago, explicações para a quebra do tratado.

No canto II, há a descrição de um debate no Senado de Cartago, que finda por determinar a declaração de guerra, e a ékphrasis do escudo de Aníbal, seguida imediatamente das cenas da queda de Sagunto. Essas cenas, que ocupam os versos 2.457-707, mostram-nos os estragos que a fome causa e a inquietude de Hércules, que observa os acontecimentos e nada pode fazer em favor da cidade que ajudou a fundar, pois sabe que se cumpre a vontade da sua cruel madrasta, Juno. De fato, Juno, na epopeia de Sílio Itálico, não é de todo distinta da que conhecemos da epopeia de Virgílio: rancorosa e protetora dos cartagineses. Como os saguntinos sofrem pela lealdade extrema que devotam à aliança que têm com Roma, o que lhes impede de entrar em batalha contra os púnicos, Hércules dirige-se à Boa-Fé $(\text { Fides })^{7}$ e lhe questiona os intentos, por que permite que tanto sofrimento

${ }^{5}$ É 'o gosto imoderado da erudição antiga - fosse ela grega ou romana - pelos jogos de palavras e as etimologias duvidosas' (Colette Jourdain-Annequin, L'image de la montagne ou la géographie à l'épreuve du mythe et de l'histoire : l'exemple de la traversée des Alpes par Hannibal. DHA 25.1, 121-7, 1999, p. 113) que se vê em ação aqui, como em muitos outros trechos da epopeia siliana (cf. para citar apenas dois exemplos, os episódios da lenda de Trasimeno, que teria dado nome ao lago, no início do canto V, vv. 1-23, e de Falerno, o vinho, narrada no canto VII, vv. 161-211).

${ }^{6}$ Cf. a nota de Miniconi e Devallet (Silius Italicus, La Guerre Punique. Tome I. Livres I-IV. Texte établi et traduit par Pierre Miniconi et Georges Devallet. Paris, Société d’Éditions “Les Belles Lettres", 1979, p. 149, n. 2). Sílio Itálico ainda explica, na sequência dos versos 1.288-90, a outra origem lendária da cidade: narra que um povo, antes sob o reinado de Laertes, moradores de uma ilha chamada Zacinto, viera instalar-se em Sagunto. 7 Traduzo por 'Boa-Fé' o nome da deusa Fides, seguindo Saraiva (F.R. Dos SAnTos SARaIVA, Novíssimo dicionário latino-português. Rio de Janeiro/Belo Horizonte, Livraria Garnier, ${ }^{12} 2006$, s.v. Fides, p. 485). Tassilo Orpheu Spalding (VIrgílio, Eneida. Trad. Tassilo Orpheu Spalding, São Paulo, Cultrix, 1981, pp. 17 e 270 n.13) e Filinto Elysio (FILinto Elysio, Obras completas de Filinto Elysio, Tomo I, Paris, A. Bobée, 1817, pp. 357), 
continue. Impotente também ela diante daquilo que já está determinado pelos Fados, a deusa se compromete a dar força e um fim glorioso aos saguntinos. Desce do Olimpo e se põe entre os sofredores na Hispânia. É nesse momento que aparece Juno, e é aqui que se encontra, na sequência dos versos 2.526-52, a descrição de Tisífone que nos interessa neste estudo. Leiamos o texto latino e, em seguida, a tradução poética de Filinto Elysio.

Quam simul inuisae gentis conspexit in arce, forte ferens sese Libycis Saturnia castris, uirgineum increpitat miscentem bella furorem atque, ita turbata gradum, ciet ocius atram Tisiphonen, imos agitantem uerbere manes, 530 et palmas tendens: 'Hos', inquit, 'noctis alumna, hos muros impelle manu populumque ferocem dextris sterne suis; Iuno iubet, ipsa propinqua effectus studiumque tuum de nube uidebo. Illa deos summumque Iouem turbantia tela, 535 quis Acheronta moues, flammam immanesque chelydros, stridoremque tuum, quo territa comprimit ora Cerberus, ac, mixto quae spumant felle, uenena et quicquid scelerum, poenarum quicquid et irae pectore fecundo coquitur tibi, congere praeceps in Rutulos totamque Erebo demitte Saguntum. Hac mercede Fides constet delapsa per auras'. Sic uoce instimulans dextra dea concita saeuam Eumenida incussit muris; tremuitque repente mons circum, et grauior sonuit per litora fluctus.

Sibilat insurgens capiti et turgentia circa multus colla micat squalenti tergore serpens. Mors graditur, uasto caua pandens guttura rictu, casuroque inhiat populo: tunc Luctus et atri pectora circumstant Planctus Maerorque Dolorque, atque omnes adsunt Poenae, formaque trifauci personat insomnis lacrimosae Ianitor aulae. ${ }^{8}$

bem como Grimal (Pierre Grimal, Dicionário da mitologia grega e romana, trad. Victor Jabouille, Rio de Janeiro, Bertrand do Brasil, 1992, s.v. Fé, p. 167) apresentam a tradução 'Fé', este último referindo-nos ao verbete Fides (id., p. 170) e o primeiro apresentando, na nota explicativa citada, o nome 'Boa-Fé'. Comparem-se as traduções de Bento Prado de Almeida Ferraz, 'Fidelidade' (cf. Horácıo, Odes e Epodos, trad. Bento Prado de Almeida Ferraz, São Paulo, Martins Fontes, 2003, p. 85), e de Sandra Bianchet, 'Confiança' (Cf. PETRÔNIO, Satyricon, trad. Sandra Braga Bianchet, Belo Horizonte, Crisálida, 2004, p. 237).

${ }^{8}$ O texto apresentado é o da edição "Les Belles Lettres". 
Juno que acaso vem das Libyas tendas, Vendo a Fé nos merlões ${ }^{10}$ da gente odiada,

Lhe estranha a furia, com que trava as guerras;

E confundindo os passos, de raivosa,

Chama appressada a lûrida Tisîphone,

Que exerce o açoute nos profundos Manes.

Diz-lhe, (e aponta-os co'a mão) 'Filha da Noite

'Abala-me esses muros: Juno o ordêna.

'Por suas proprias dextras me derruba

'Esse Povo feróz. D'aquî na nuvem

'Verei de pérto o effeito, e a ancia da obra.

'As armas, com que móves o Acheronte

'Com que os Deoses, e o summo Jóve enturvas;

'As chammas, e os Chelydros inhumanos,

'E os teus rugidos, que a medrósa tromba

'Do Cérbero comprimem, e esses venênos,

'Que mésclados com fél, bólhão espumas;

'Quanta amargura, no fecundo peito,

'E quanta ráiva cózes, présto arrója-as

'Contra os Rútulos: lança éssa Sagunto

'Inteira no Érebo. Tal prémio ganhe

'A Fé, por ter do Pólo aquî baixado.'

Pungindo-a assim co'a vóz a irosa Juno

Co'a dextra empuxa a Furia séva aos muros :

De repente, em redór, tremeo a sérra, E máis gráve, na práia, o mar sôou.

Muita serpente, alçando-se na fronte

Lhe silva, e com os lombos escamosos, ${ }^{11}$

Lhe luz em tôrno da cerviz inchada.

C'o vasto queixo abérto vem a Mórte,

E as cavadas guélas mostra, anciando,

A gente devorar perecedoura.

Então o Pranto, a Dôr, o negro Nôjo ${ }^{12}$

\footnotetext{
${ }^{9}$ Nota de Filinto Elysio (p. 356, n. 1): 'Não quér o Poéta que a Senhora Juno venha do mercado; mas sim das tendas do exército Carthaginez. Bem cérto fico de que os benévelos [sic] Leitores lhe farão esse favor, pela sua innata bondade'.

${ }^{10}$ Nota de Filinto Elysio (p. 356, n. 2): 'Como tambem aquî por merlões entende o Poéta a Cidadella, e ainda todo o interior dos muros de Sagunto. Os Poétas (como os meus sabios Leitores tem na ponta da lingua) usão da parte pelo todo, e do todo pela parte'.

${ }^{11}$ Nota de Filinto Elysio (p. 357, n. 1): Escamosos squalenti. - Macrobius $6^{\circ}$. Saturnal. cap. $7^{\circ}$. Squalere enim dictum est ab squamorum crebritate asperitateque, quae in serpentum pisciumue cosiis uisuntur.

${ }^{12}$ Nota de Filinto Elysio (p. 357, n. 2): 'Não tenhão nôjo do vérso; que este nôjo não é náusea, é lucto: é aquelle nôjo de que diz Camões: 'Ah! que não sei, de nôjo, como o conte!' Assim como o Olympo é celebrado pelas [sic] Poétas como aula gozosa, e são tambem gozosos cinco mysterios do Rosario, tambem ao inférno chamão aula chorosa'.
} 
Com a Tristeza os peitos lhe rodêão.

Tudo o que é mágoas vêm allî presente, E o Guarda velador da aula dos prantos

Das tres fáuces despéde tres latidos.

Enquanto a deusa Boa-Fé acompanha os sofrimentos dos saguntinos, tendo descido do Olimpo para apoiá-los, Juno, que casualmente passa por aquelas paragens, resolve iniciar sua intervenção e chamar a deusa infernal, Tisífone, para pôr fogo aos inícios da guerra. A cena, construída a partir da casualidade da passagem de Juno, retoma o modelo virgiliano: no canto VII da Eneida, Juno traça um caminho que vai da cidade de Argos, onde tinha um dos principais centros dos cultos dedicados a si, para Cartago, se aceitarmos a interpretação de Cunha ${ }^{13}$. No seu caminho, Juno vê Eneias e troianos; eis os versos (En. 7.286-9):

Ecce autem Inachiis sese referebat ab Argis

Saeua Iouis coniunx, aurasque inuecta tenebat, Et laetum Aenean classemque ex aethere longe Dardaniam Siculo prospexit ab usque Pachyno.

Eis que de volta da bela cidade fundada por Ínaco a fera esposa de Jove, ao cruzar com o seu carro as alturas, ao longe avista na bela Sicília, ao dobrar o Paquino cabo, o Troiano caudilho exultante e seus barcos velozes, bem como os Teucros valentes, no afã de construírem moradas e de saírem das naves. ${ }^{14}$

É, então, casual a passagem de Juno pela cena, assim como é casual, em Sílio Itálico, a passagem da deusa por Sagunto; a partir dessas visões, no meio do caminho que fazia, é que Juno decide invocar as forças infernais em seu auxílio: a Alecto, na Eneida; a Tisífone, nas Púnicas.

Numa nota à sua edição escolar da Eneida, o Pe. Arlindo Ribeiro da $\mathrm{Cunha}^{15}$, sobre o verso 286, ensina que se deve subentender a expressão in urbem Cartaginem, "em direção à cidade de Cartago", supondo que Juno, vindo de Argos, dirige-se, na cena virgiliana, para a cidadela da sua protegida africana. A opção de Sílio é menos clara: se, no início do verso

${ }_{13}$ Vergilius, Aeneis, texto completo anotado pelo Pe. Arlindo Ribeiro da Cunha, Braga, Livraria Cruz, 1948, p. 435, nota ao verso 286, ad finem; cf. desenvolvimento a seguir.

${ }^{14}$ A tradução da Eneida que se apresenta nesta citação é de Carlos Alberto Nunes (Vergílio, Eneida, trad. Carlos Alberto Nunes, São Paulo, A Montanha Edições, 1981). Estes versos da tradução, 7.286-91, encontram-se na p. 144.

${ }^{15}$ Vergilius, 1948, p. 435. 
527, por meio mesmo da aliteração forte ferens, marca-se a casualidade da passagem da deusa pelos muros de Sagunto, não fica claro de onde ela vem - nem sequer para onde vai. Se não, vejamos: a expressão Libycis castris pode ser lida como um ablativo de lugar de onde, indicando o ponto de partida do passeio da deusa; assim, ela estaria vindo de Cartago, 'dos acampamentos líbios' ou 'das líbias tendas', como Filinto Elysio nos traduz o passo. A mesma expressão Libycis castris, contudo, pode ser interpretada como um dativo de destinação, construção que é poética e própria do latim imperial ${ }^{16}$, empregada em lugar de in Libyca castra ou ad Libyca castra; assim, Juno estaria indo para Cartago, 'em direção aos acampamentos líbios' ou 'para as líbias tendas' ${ }^{17}$. Essa incerteza, aqui em relação aos pontos de partida e de chegada dos andores da divindade, como veremos, dissemina-se ao longo de toda a passagem - e é significativa.

O andar da deusa, ao contrário do que se esperaria, não é firme e seguro, mas incerto, perturbado pela ira que ela sente (ira turbata gradum, "[a deusa] perturbada nos seus passos pela ira", v. 529). Este verso, ademais, é todo construído sobre uma aliteração em oclusivas, como que a mimetizar o andar irregular: atque, ira turbata gradum, ciet ocius atram. Spaltenstein ${ }^{18}$ explica o passo: 'turbata exprime claramente: a desordem do seu andar transcreve pitorescamente a conturbação dos seus sentimentos'. A 'conturbação dos sentimentos', designadamente causada pela ira, é característica própria de Juno na Eneida, em que a deusa é frequentemente qualificada pelo adjetivo saeua, "seva", "cruel"19. Na configuração siliana, no entanto, a deusa toma para si outro adjetivo, que a acompanhará ao longo de todo o poema: a Juno de Sílio Itálico é turbata, "perturbada", "conturbada", "alarmada", "irritada" ${ }^{20}$. Além da passagem sob análise, em que ela é as-

${ }^{16}$ Cf. Ernesto Faria, Gramática Superior da Lingua Latina. Rio de Janeiro, Livraria Acadêmica, 1958, p. 354, § 61 .

${ }^{17}$ Tradução adotada por Duff(Silius Italicus, Punica, transl. J. D. Duff, vol. I, Cambridge, Massachussetts, Harvard University Press; London, William Heinemann Ltd., 1983, p. 99), Miniconi e Devallet (Silius Italicus, 1979, p. 59a) e Villalba Álvarez (Silıo ItÁLICO, La guerra púnica, trad. Joaquín Villalba Álvarez, Madrid, Ediciones Akal, 2005, p. 199).

${ }^{18}$ François Spaltenstein, Commentaire des Punica de Silius Italicus (livres 1 à 8). Genève, Librairie Droz S.A., 1986, p. 158.

${ }^{19}$ Para citar dois exemplos, ela é assim descrita na proposição da Eneida (saeuae ... Iunonis, 1.4), quando Virgílio explica a causa fundamental das provações de Eneias e sua frota; e também em Eneida 7.287, parte da passagem que comentamos acima, quando, enfurecida por ver os sucessos do povo troiano em solo italiano, Juno resolve invocar Alecto e dar início à guerra entre troianos e latinos: saeua Iouis coniunx. Cf. Peter E. Knox, Savagery in the Aeneid and Virgil's ancient commentators, CJ 92.3, 225-33, 1997. ${ }^{20}$ D.C. Feeney, The Gods in Epic. Oxford, Clarendon Press, 1991, p. 303. 
sim descrita no v. 529, Juno será caracterizada como turbata em ao menos três outras passagens. Em 10.337, após a batalha de Canas, conhecedora da impossibilidade de vitória, Juno se serve do Sonho para dissuadir Aníbal de atacar Roma, decisão que o general cartaginês acabara de tomar; nesse verso, a deusa é descrita como turbata... coniux Saturnia, "alarmada ... a esposa Satúrnia". No canto XII, novamente decidido a atacar Roma, Aníbal é novamente dissuadido por Juno, que, após o terceiro dia de tentativas frustradas do general, lhe desvenda a oposição das divindades olímpicas à empreitada cartaginesa; nessa passagem, mais uma vez, é-nos Juno apresentada como turbata... Saturnia, "alarmada ... a Satúrnia" (12.701-2). No último canto do poema, Juno lança uma sombra de Aníbal diante dos olhos de Cipião, que, no campo de batalha, em Zama, procurava travar combate singular contra o general cartaginês; da mesma forma, ela também engana Aníbal, pondo diante dos seus olhos uma sombra de Cipião, que, seguida, afasta o general cartaginês do campo de batalha. Uma vez descoberta a falácia, Aníbal se desespera, mas Juno trama nova artimanha: sob a imagem de um pastor que promete guiá-lo por um atalho, a deusa, do topo de um monte, apresenta a Aníbal a batalha perdida, retornando em seguida para o Olimpo. Na cena desse retorno, a deusa nos é descrita como Iuno... turbata, "Juno... perturbada" (17.604).

Passemos à figura da divindade infernal, Tisífone, percorrendo o seguinte caminho: primeiro, comentaremos a formação de seu séquito, catalogado entre os versos 548-52; segundo, as alterações espaciais que sua presença causa, vv. 543-45; terceiro, o mandado, a missão delegada à Fúria, que se lê no conjunto dos versos 531-4 e 538-42; por fim, deter-nosemos nas descrições de Tisífone, a primeira delas nas palavras de Juno (vv. 535-8), a segunda na voz do próprio poeta (vv. 546-7).

É comum vermos os deuses serem seguidos de uma comitiva, como Vênus, que se faz acompanhar das Graças, e Baco, de suas mênades e do velho Sileno. Nas Púnicas (4.430-44), por exemplo, Marte é seguido pela Ira, pelas Eumênides, por Belona. No passo que temos sob análise, Sílio Itálico apresenta seis personificações como acompanhantes de Tisífone: a Morte, o Luto (que Filinto Elysio traduz 'Nojo', justificando-se em nota de pé de página ${ }^{21}$ ), o Pranto, a Tristeza, a Dor e as Penas, além do cão infernal, Cérbero, que não a segue propriamente, mas se faz ouvir²2 .

${ }^{21}$ Cf. n. 12, supra.

${ }^{22}$ Lembro aqui a hipótese aventada por Waszink de que um dos nomes latinos (uulgata nomina) das Fúrias fosse Agmentae, relacionado sobretudo a Tisífone: ea quae agmina ducit?, "aquela que lidera os exércitos?", pergunta-se o crítico. (Cf. J.H. WAszink, Agmina Furiarum. The Harvard Theological Review 56.1, 7-11, 1963, p. 9). 
A Morte, divindade que personifica uma abstração, merece destaque. O segundo hemistíquio do primeiro verso (548) em que ela aparece representada é mimético: no meio, a boca se abrindo (pandens); a goela cresce (caua... guttura); e, por fim, os lábios, a boca propriamente dita, enormes (uasto... rictu), servindo de moldura a tudo isso, para que ela possa engolir todo o povo saguntino (inhiat populo), que está destinado à queda, à morte (casuro). E notemos que a Morte se adianta (graditur); e o verbo utilizado tem o mesmo radical que aquele substantivo que nos explicava, no v. 529, como estava perturbada a deusa Juno: quanto aos seus passos, nos seus passos (gradum). A deusa Juno, no entanto, anda incerta no começo do trecho, cheia da conturbação dos seus sentimentos; a Morte, que acompanha Tisífone, tem passo seguro, ao contrário de Juno; ela marcha e se adianta para cumprir a sua tarefa.

O Luto é comum e recorrente como acompanhante de Tisífone: ele está no inferno virgiliano (En. 6.274), nas Metamorfoses de Ovídio (4.484) e mesmo na tragédia Édipo de Sêneca (592), em que é descrito como o que 'arranca os cabelos' (auellens comam). Nas Púnicas mesmas, ele volta a ser representado nos infernos, numa passagem do canto XIII, em que é qualificado de edax (13.581): o Luto que corrói.

'Pranto' parece ser aqui o único exemplo de personificação dessa abstração. E o que é o Pranto? A tradução que nos apresentam tanto Saraiva quanto o Oxford Latin Dictionary dá, como primeira acepção, a 'ação de bater com ruído, pancada, batedura' ${ }^{23}$. 'Pranto' (Planctus), então, parece fazer referência ao ato de auto-flagelação que se impõem aqueles que carpem a morte de um ente querido.

Nos versos 549 e 550, a expressão atri / pectora, "negros quanto ao semblante", ao pé da letra, poderia se referir a todas essas divindades que estão de pé, em círculo (circumstant) - o Luto, o Pranto, a Tristeza e a Dor - ou somente às duas divindades mais próximas do qualificativo, Luctus, o Luto, e Planctus, o Pranto. Esta é, por exemplo, a interpretação de Miniconi e Devallet, tradutores da edição Belles Lettres ${ }^{24}$. Quanto à cor negra, Spaltenstein explica o seu valor em três passagens distintas: é a expressão de uma 'ideia dramática, terrível', que 'sugere simplesmente ideias associadas ao luto, à tristeza, à morte' e aparece em expressão equivalente aos infernos e a tudo que com eles tenha relação $0^{25}$.

\footnotetext{
${ }^{23}$ Saraiva, p. 905, s.v. Planctus, us; P. G. W. Glare et al. Oxford Latin Dictionary. Oxford, Oxford University Press; New York, Clarendon Press, 1968, p. 1387, s.v. planctus, us.

${ }^{24}$ Silius Italicus, 1979, p. 60a.

${ }^{25}$ Cf. Spaltenstein, pp. 75 e 158.
} 
A lista segue com a Tristeza (Maeror) e a Dor (Dolor). A Tristeza, que, como o Pranto, parece ter aqui sua única personificação, encontrase mencionada novamente no canto XIII, quando Sílio Itálico a descreve como a que se alimentou de choro (pastus Fletu, 13.582). Dolor, a Dor, na verdade, está sempre ligada a Maeror e, não diferentemente do que acontece com Planctus, tem aqui o único registro da sua personificação.

Por fim, Sílio nos mostra presentes as Poenae, que não comparecem na tradução de Filinto Elysio. O nome dá margem a pelo menos duas interpretações. A primeira, em que o tomamos de fato por Pena, divindade que não é mais que

a personificação da vingança ou do castigo. É por vezes identificada com as Erínias, suas companheiras. Na mitologia romana tardia, Poena é a mãe das Fúrias (as Erínias) e figura entre as divindades infernais. Mas trata-se de uma concepção poética, alegórica, alheia à mitologia propriamente dita. ${ }^{26}$

É a essa divindade que Tibulo se refere, em 1.9.4, como 'lenta, no entanto, chega com passos silenciosos' (sera tamen tacitis Poena uenit pedibus) e Horácio, na Ode 3.2.31, a chama de 'Pena do pé claudicante' (pede Poena claudo). Mas ela pode também ser identificada com as próprias Fúrias, divindades infernais que são, em princípio, as que vingam os crimes cometidos pelos mortais, sobretudo os crimes que se voltaram contra parentes. Essas divindades são conhecidas também pelos nomes gregos de Erínias (ligado, em duas etimologias fantasiosas, a orínein, "perseguir com furor", e a erinýein, "estar furioso") ou Eumênides ("as benfazejas", nome eufemista e apotropaico). São três irmãs: Alecto, 'a que não pára, a incessante, a implacável'; Megera, 'a que inveja, a que tem aversão por'; e Tisífone, 'a que avalia o homicídio, a vingadora do crime ${ }^{27}$. Como o texto nos apresenta a palavra Poenae, no plural, parece-nos antes que se trate das Fúrias, neste caso, Alecto e Megera, que acompanhariam sua irmã, Tisífone, protagonista da cena ${ }^{28}$. Assim também interpretou Duff, que traduz o nome por Avengers, as vingadoras ${ }^{29}$.

Por último, Cérbero, o cão de três cabeças que guarda a entrada dos Infernos, é, por essa função, chamado Ianitor, "porteiro" da 'morada das

${ }^{26}$ Grimal, 1992: 364.

${ }^{27}$ Junito de Souza Brandẽo, Mitologia grega, vol. I, Petrópolis, RJ, Vozes, ${ }^{21} 2009$, p. 217-8.

${ }^{28}$ Sobre a 'concepção clássica' de que as Fúrias seriam três e as discordâncias de tal concepção, cf. Robert J. Edgeworth, Virgil's Furies, The Harvard Theological Review 76.3, 365-7, 1983.

${ }^{29}$ Silius Italicus, 1983, p. 101. 
lágrimas' (aulae lacrimosae, 552). Ele, ao sentir a presença de Tisífone, não dorme (insomnis) e late forte (personat), com a sua aparência própria, as três goelas (forma trifauci, 551). Ele é representado ainda nos versos 537 e 538, em que Juno declara que, tendo ouvido o som da voz de Tisífone, Cérbero se cala, temeroso. Essa cena é tanto mais significativa quanto, no canto XIII, Sílio descreve o furor do mesmo cão, quando, uma vez liberado das suas amarras, percorre o Tártaro e late, enroscando as víboras da sua cauda em torno do seu flanco e, diz o poeta, 'nem a própria Alecto, nem Megera, fecunda em furor, ousam aproximar-se da fera' (non ipsa Alecto, non feta furore Megaera / audet adire ferum, 13.592-3).

Uma vez visto o séquito de Tisífone, passemos agora por onde ela anda. Voltamo-nos para a análise dos versos 543-5, que descrevem as alterações no espaço geográfico que a presença da Fúria causa.

O primeiro verso e meio (543-4) nos desenha como, após dar suas ordens, a deusa Juno lança a Fúria contra os muros de Cartago. O verbo utilizado, concussit, poderia ser traduzido por 'lançou' ou 'instigou'. Para a primeira dessas duas possibilidades, visualize-se que esse é o verbo que se usa no sentido de 'brandir', com referência a uma lança, por exemplo. E repare-se que a deusa Juno lança sua serva Fúria com a mão direita, dextra (543), palavra que se destaca pela aliteração com dea, com que forma um conjunto enfatizado, no verso, também pela posição que ocupa, logo após a cesura. Dextra, a "destra", é a mão com que se fere o inimigo; é, em geral, a mão que carrega a arma, em oposição à esquerda, que se protege com o escudo. Em concussit, então, temos que a deusa Juno brandiu, lançou a sua $\operatorname{arma}^{30}$. Há ainda uma ideia de som: quatio, de que se forma concutio, é o verbo usado para descrever o bater das asas de um pássaro e o vibrar do chão com o galopar do cavalo. A sinestesia que se percebe em concussit, sentimo-la também em tremuit (544), em que o tremor do monte se vê e se

${ }^{30} \mathrm{Cf}$. S. Franchet D'Espèrey, Variations épiques sur un thème animalier, REL (55e année), 157-172, 1978. Nesse artigo, a autora desenvolve um estudo central, que dá título ao artigo ('Variações épicas sobre um tema animal'), por meio de temas subjacentes, como o da Fúria. No exame desse tema, ela chega à conclusão de que a Fúria que aparece no canto VII da Eneida não é exatamente a mesma que a Erínia grega, 'deusa do castigo, da vingança e do remorso' (p. 159), mas mero instrumento nas mãos de Juno, que se serve da Fúria para provocar o enfrentamento entre troianos e latinos. Apontando que se trata de uma forma encontrada por Virgílio, que tinha a intenção de apresentar os troianos sob uma boa imagem e não como salteadores, como o fizeram outros autores, D'Espèrey julga que a intervenção divina é um mecanismo épico, na Eneida, que serve para dar à ação dos troianos 'uma causa acidental, que lhes tirasse toda a culpa'. Se aceitamos a interpretação de D’Espèrey, é, contudo, pouco provável que a mesma intenção tenha norteado a imaginação do passo em Sílio Itálico; nessa nuança inicial, o tema virgiliano é reaproveitado por Sílio, que, como veremos, introduz uma mudança na sua leitura da cena. 
ouve; e em sonuit (545), em que ouvimos a onda, mais pesada (grauior, 545), espalhar o seu ruído pela praia. E por toda a praia: a expressão per litora (545) encontra-se cercada, no verso, pelo verbo sonuit e pelo seu sujeito, fluctus, "a onda", como se a sintaxe, num desenho mimético, pintasse a cena.

O aprisionamento da orla pelo ruído da onda é somente mais uma manifestação da noção de circunferência que se espraia por esses versos: Tisífone é lançada contra os muros (muris, 544, e muros, 532), que são a circunferência protetora da cidade de Sagunto; o monte que tremeu, com a chegada da Fúria, tremeu todo em volta de si, circum (545). Lembremos ainda que o Luto, o Pranto, a Tristeza e a Dor (549 e 550), que já analisamos, apresentam-se todos em volta (circumstant, 550) da Morte, ela também parte da comitiva de Tisífone. As ondas, por sua vez, e a utilização que Sílio faz da movimentação marítima foram estudadas por Manolaraki ${ }^{31}$, que mostra como o poeta se instaura numa posição de superioridade visual e explica as causas cósmicas dos acontecimentos, sejam esses decodificados pelas personagens que os presenciam ou não. Ademais, a ocorrência de tais descrições, como ekphráseis, fazem parte da própria estruturação do poema. O que se vê nesses versos não é pequeno detalhe sinestésico; trata-se, antes, de elementos recorrentes da poética siliana que se prestam à construção da cena e da sua própria versão da fúria.

Detenhamo-nos agora no que Tisífone deve fazer: a missão que lhe é atribuída por Juno; passemos ao comentário dos versos 531-4 e 538-42. Uma primeira questão que se nos apresenta é a da forma como vem descrito o pedido de Juno. Palmas tendens (531) significa 'estendendo as palmas/as mãos', frequentemente a expressão de um ato de súplica. Poderia Juno suplicar a uma deusa que lhe é inferior, uma divindade menor, infernal? Daí que se cogite uma segunda interpretação para o gesto: levando-se em consideração a fala de Juno, em que hos (531) aparece no início, logo após a cesura do verso, e repetido no início do verso seguinte, a deusa pode ter as palmas estendidas para mostrar a cidade de Sagunto, caracterizada, aliás, como populum ferocem (532). A tradução de Filinto Elysio não só lê a cena dessa forma, como adiciona (no sétimo verso da sequência que transcrevemos supra) 'e aponta-os co’a mão'; assim também Miniconi e Devallet, em cuja tradução Juno diz: 'Tu vês estes muros' - e os tradutores franceses acrescentam: 'diz-lhe ela com um gesto da mão' (grifos nossos) ${ }^{32}$. Por fim, considere-se ainda a tradução de Nisard, que dá mais ênfase à ordem com

${ }^{31}$ Eleni Manolaraki, 'Silius' Natural History: Tides in the Punica' in Antony AugousTAKIS (ed.), Brill's Companion to Silius Italicus, Leiden/Boston, Brill, 2010, pp. 293-321. 32 '[...] “tu vois ces murs", lui dit-elle avec un geste de la main' (Silius Italicus, 1979, p. 59a). 
o verbo gritar: '- Filha da noite - grita-lhe, estendendo a mão em direção a Sagunto - tu vês estes muros' ${ }^{33}$.

Ferocem, no v. 532, está por 'belicoso': Juno vê Sagunto como cidade belicosa, que lhe faz guerra e, paradoxalmente, lhe faz guerra por não fazer guerra contra seus sitiantes, os cartagineses. A ordem, então, é para Tisífone impelir (impelle, 532) com a própria mão ( $m a n u$ ) o povo que hesita; colocar em ação, com uma mão, as várias destras (dextris, 533) que levarão os sitiados à morte. Vimos o valor da palavra dextra, que aqui ocorre no plural e, que é mais, acompanhada de suis: os saguntinos não só se imporão a morte, mas, com suas próprias destras, o suicídio; muitas mãos, impotentes, no entanto, diante da única mão da Fúria: um suicídio coletivo, descrito minuciosamente nos versos seguintes, que concluirão o canto, será o resultado da ação de Tisífone.

Nas palavras de Marks $^{34}$, Sagunto é o Doppelgänger de Roma: o suicídio dessa cidade, motivado pela fides, um valor tipicamente romano, faz dela uma espécie de vítima expiatória que ocupa o lugar de Roma - é graças à queda de Sagunto, no início da guerra e do poema, que Roma poderá manter-se de pé ao fim da guerra - e do poema. E P. Hardie, num capítulo intitulado Sacrifice and substitution ("Sacrifício e substituição"), corrobora essa interpretação: 'o sacrifício opera por meio da substituição e da troca [...]. A própria vítima tem valor simbólico, substituindo quem a oferece ${ }^{35}$. Além disso, a queda da aliada Sagunto, no canto II, prepara o leitor para a queda da inimiga Cartago, no canto XVII; a substituição do indevido pelo devido, da morte de Sagunto para que Roma possa enaltecer-se, e a recuperação da honra romana pelo fim de Cartago, não deixa de ter, ela também, as suas raízes virgilianas: também a Eneida traz a queda de uma cidade, Troia, narrada no canto II, para que Roma possa surgir; a partir do canto VIII, a guerra que dará fim à oposição, sob o comando de Turno, das cidades italianas ao estabelecimento da nova Troia mostra em que medida Sílio está na sucessão do grande épico latino ${ }^{36}$.

33 ، "Fille de la nuit, lui crie-t-elle en étendant la main vers Sagonte, tu vois ces murs" [...]' (Lucain; Silius Italicus; Claudien, Oeuvres complètes, trad. M. Nisard, Paris, J.-J. Dubochet et Compagnie, 1857, p. 242). Note-se ainda que bem antes, em 1827, as duas possibilidades de leitura da expressão que destacamos estava já assinalada no comentário de Lemaire (Silius Italicus, Punicorum libri septemdecim, ed. N. E. Lemaire, vol. I, Parisiis, Bibliotheca Classica Latina, 1827, p. 134, n. ao v. 531).

${ }^{34}$ R. Marks, 'Silius Italicus', p. 534.

${ }^{35}$ Philip Hardie, The epic successors of Virgil: a study in the dynamics of a tradition. Cambridge, Cambridge University Press, 1993, p. 32.

${ }^{36}$ Michael von Albrecht, Historia de la Literatura Romana, vol. II, Barcelona, Herder, 1999, pp. 888-9. 
Tisífone deve, então, com sua própria mão, pôr abaixo a cidade de Sagunto, porque Juno assim o ordena: Iuno iubet, expressão que aparece, no meio do verso 534, destacada pela pausa da cesura, a que segue, além da repetição da primeira sílaba nas duas palavras justapostas. O mesmo verso inicia uma aliteração em oclusivas, com ênfase nas bilabiais (ipsa propinqua), que se retomará no fim do verso seguinte (de nube uidebo). É curioso o emprego da palavra propinqua: palavra que significa 'próxima' e que registra, entre suas acepções, por extensão semântica, 'aparentada'.

O segundo trecho (vv. 538-42) se inicia com a mistura que Juno determina: os venenos e o fel da Fúria. A menção ao paladar nos remete à sinestesia própria do passo, já comentada; o verso, por sua vez, é desenhado para os nossos olhos: a mistura dos venenos (uenena) com o fel (felle) se sugere na inusitada quebra da construção do ablativo absoluto mixto felle, que se interrompe - e mescla - com a relativa quae spumant que se refere a uenena, no fim do verso ${ }^{37}$. Mimeticamente, a mistura ainda se representa no quiasmo do verso seguinte (540); semanticamente, nos verbos coquitur e congere do verso 541. O primeiro, coquitur, é o verbo coquo, "cozinhar", na voz passiva; logo, Juno pede, ao pé da letra, que Tisífone utilize o que quer que ela tenha de crimes, de castigos, de ira, em suma, o que quer que 'cozinhe' no 'peito fecundo' (pectore fecundo, 540) ${ }^{38}$. O segundo verbo, congere, significa propriamente 'gerenciar', 'colecionar', 'pôr junto' - e Tisífone deve pôr junto quanto ela tiver de crimes, castigos e ira, tudo quanto ela incita no seu peito fértil em ardis infernais. A violência que lhe é outorgada se imprime ainda em três palavras que se sucedem: a primeira delas, concluindo o verso 540, praeceps, determina como Tisífone deve 'gerenciar' os elementos que se excitam no seu peito contra os rútulos (in Rutulos, 541) - de forma precipitada; a segunda, demitte, no verso 541, destacada pela pausa da cesura, explicita a queda de Sagunto, que deve ser por completo enviada ao Érebo; por fim, o cenário de desalento que a ação da Fúria deve deixar é justificado na desdita do pagamento, devido pelos saguntinos, por terem feito descer (delapsa, 542) a deusa Boa-Fé. Observem-se os prevérbios de movimento ( prae- e de-) que entram na composição desses termos, e a forma como contribuem para a construção semântica da cena.

Há, reiteremos, uma imagem de mescla de que se deixa imbuir o texto: vimos que comparece em estruturas sintáticas, mimetizando o que

${ }^{37}$ Veja-se, a propósito, no canto XIII, quando da descrição dos rios infernais, que é o Aqueronte 'o mais funesto pela peçonha e pelo espesso veneno' (tristior his Acheron sanie crassoque ueneno, 571), e 'são essas as bebidas de Tisífone' (haec et Tisiphones sunt pocula, 575). ${ }^{38} \mathrm{Na}$ Eneida (fecundum concute pectus, 7.338), 'peito fecundo' é o que deve agitar (e notese que o verbo não é outro senão concutere) a Fúria Alecto, para cumprir as ordens de Juno. 
se diz; que aparece nas figuras da sinestesia e do quiasmo; que se apresenta, ainda que menos claramente, na noção de circunferência que perpassa o texto. Até aqui, vimos diversas características do texto que, en passant, acabam por nos delinear uma figura da Fúria Tisífone por vias indiretas, pois sabemos com quem anda, como anda e o que seu andar causa, para que anda - qual missão lhe é atribuída. Passemos, então, às descrições propriamente ditas da Fúria: as que se encontram no intervalo dos versos 529-30, 535-8 e no dístico 546-7.

Tisífone é 'filha da noite' (noctis alumna, 531); é assim que Juno se dirige a ela, esse é o seu vocativo. Em consequência dessa variação do mito adotada por Sílio Itálico, ela é, então, negra (atram, 529). Tisífone é a vingadora do crime; o crime, aqui, é a insistência dos saguntinos em manter a sua fidelidade à aliança com Roma. Com isso, mantêm a sua fidelidade à deusa Boa-Fé; com isso, também enraivecem Juno, que, em prol dos cartagineses, deseja que a guerra se instaure. Pois a negra Tisífone castigará os culpados ao lado dos seus negros acompanhantes, o Luto e o Pranto, a Tristeza e a Dor, antes descritos como negros 'quanto ao semblante' (tradução do acusativo de relação pectora, 550). Para Tisífone não há acusativo grego, não há delimitação; é ela todo negra, com todas as possibilidades semânticas que tem essa configuração. Nessa descrição, se Tisífone se 'mescla', se ela se identifica com os seres infernais que a acompanham, fica clara também a maior extensão que lhe cabe na característica partilhada.

Das três fúrias, Tisífone é a que mais frequentemente é representada como a que fustiga, e Juno invoca a deusa 'que atormenta os espíritos inferiores com um chicote' (imos agitantem uerbere manes, 530), para que, a partir do v. 535, tenhamos a lista do que ela espera que Tisífone seja capaz de pôr em ação contra os saguntinos; além dos venenos (uenena, 538), o que quer que ela tenha de crimes (quicquid scelerum, 539), de castigos o que quer que ela tenha (poenarum quicquid, 539) e de ira (irae, 539), a Fúria deve usar das suas armas (tela, 535, propriamente 'dardos'), que, aqui, não são os chicotes. Dardos com que ela é capaz de atormentar (e aqui o verbo não é outro senão turbare, 535) os deuses e o maior deles, o próprio Júpiter (illa deos summumque Iouem turbantia tela, 535). Tisífone atormenta as almas nos infernos, os deuses no Olimpo, inclusive o maior deles, e altera a paisagem do mundo, como vimos; leva todo um povo ao suicídio coletivo, como se lê na sequência desse canto; em suma, o seu poder de atuação se confunde em diferentes níveis ${ }^{39}$.

${ }^{39}$ Como os Gigantes que, gerados no interior da Terra, abalaram a terra e os céus. Segundo Marks, 'dois paradigmas contrastantes condicionam o manuseio de Sílio das relações com 
Tisífone, fisicamente, é ainda a que tem o fogo, a chama (flammam, 536); terríficas serpentes (immanes chelydros, 536) na cabeça; sua voz é um ruído, um som agudo, um zumbido (stridor, 537). Há aqui o fogo, o calor, tátil; as serpentes que se veem, horrorosas, a visão; o som que a deusa-monstro produz, a audição: eis-nos de novo diante da sinestesia. Há, no entanto, muito mais nessa descrição. A chama a que se refere Sílio Itálico é provavelmente o archote, arma comumente representada na mão das Fúrias; desnecessário talvez fosse lembrar aqui a cena em que Alecto ateia o furor do desejo bélico no peito de Turno, no canto VII da Eneida ${ }^{40}$.

É curioso notar que as cobras que formam a cabeleira da Fúria vêm descritas pela palavra chelydrus, grega. Põem-se de acordo os dicionários no indicar que se trata de uma cobra anfíbia, acrescentando-nos que é também peçonhenta ${ }^{41}$. Há ao menos três outros registros do mesmo termo nas Púnicas: em 1.412 e em 8.496, descreve o poeta a capacidade de guerreiros no encantar esse tipo de cobras, pô-las para dormir ou desarmá-las do seu veneno ${ }^{42}$; em 3.316, a referência é às conhecidas pestes da cabeça da Medusa. Não seria demasiado ousado, então, concluirmos que o uso do termo, em Sílio Itálico, parece estar ligado, por um lado, à força mágica que exercem os que podem controlar tais bestas, e, por outro, à fluidez que seus movimentos anfíbios apresentam. E Sílio insiste nessa combinação: nos versos 547-8, o poeta, não mais na voz de Juno, mas por ele mesmo, descreve-nos a cabeça de Tisífone, em que, erguendo-se, silvam muitas serpentes (aqui o termo já é o aparentemente mais corriqueiro, serpens, que reforça a aliteração em $s$ que percorre os dois versos: sibilat insurgens... multus... squalenti... serpens) de couro escamado, que se agitam em torno do pescoço que se intumesce. Como antes as ondas por onde a Fúria passava soavam por todo o litoral, aqui as serpentes silvam em torno (e revemos aqui a imagem recorrente de circularidade, de circunferência, como que em escala menor) do pescoço que se incha. Curioso notar, ainda,

os deuses nas Púnicas: a apoteose de Hércules e a Gigantomaquia' (Cf. RAYMOnd MARKs, 'Flavian variant: history. Silius' Punica' in A.J. Boyle (ed.), Roman Epic, London and New York, Routledge, 1993, pp. 227-8).

${ }^{40}$ Virg. En. 7.414-59. Em tempo: lembra-nos Spaltenstein (p. 159-60) que a representação das Fúrias munidas de um archote e com a cabeleira composta de cobras foi desenvolvida sobretudo pelos latinos.

${ }^{41}$ Cf. e.g. Saraiva, p. 211, s.v. Chelydrus, $i$; Glare et al., p. 309, s.v. chelydrus, $i$.

${ }^{42}$ Lembram-nos Volpilhac, Miniconi e Devallet que 'o dom de tornar inofensivas ou de matar as serpentes faz parte dos poderes tradicionais dos mágicos', além de notarem que o passo 8.495-7 é bastante próximo da Eneida 7.753-5. (Cf. Silius Italicus. La Guerre Punique, tome II, livres V-VIII. Texte établi et traduit par José Volpilhac (V), Pierre Miniconi et Georges Devallet (VI-VIII), Paris, Société d'Éditions “Les Belles Lettres”, 1981, p. 179.) 
que é o pescoço da Fúria que se instumesce, no texto de Sílio, não o das serpentes, como se esperaria ${ }^{43}$; em última instância, circundada por esses animais peçonhentos, é como se Tisífone ela mesma se tivesse tornado um deles, e o seu pescoço, inchado, se preparasse para lançar o veneno.

Havíamos já mencionado as armas de que Tisífone se utiliza; vimos que são capazes de atormentar os deuses e o próprio Júpiter; mas não só: elas atormentam ainda todo o Aqueronte, como fica dito no verso 536. O Aqueronte é um rio dos Infernos ${ }^{44}$, logo na entrada, cuja travessia é fundamental para as almas recém-chegadas àquelas paragens. Atravessa-se com o auxílio de Caronte, um barqueiro. Metonimicamente, o Aqueronte está, aqui, pelos Infernos. Mas há algo de muito mais importante: uma dessas 'mesclas' que vimos analisando e descobrindo ao longo de todo o texto. Uma identificação maior da divindade infernal com outra personagem: a própria Juno.

No canto VII da Eneida, Juno, em mais um movimento de expressão da sua raiva, resolve chamar uma Fúria, Alecto, em seu auxílio para fomentar os inícios da guerra entre latinos e troianos. Depois de ver os troianos já na Itália, enquanto fazia um caminho que vai da cidade de Argos, onde tinha um dos principais centros dos cultos dedicados a si, para Cartago, irada por ver que nem a tempestade causada por Éolo (canto I), nem a paixão de Dido, incentivada por Vênus (cantos I-IV), conseguiram impedir o progresso do que está determinado pelos Fados, Juno recorre aos infernos. Resolve 'revolvê-los'. É célebre o verso lapidar em que a deusa declara a sua intenção: Flectere si nequeo Superos, Acheronta mouebo (Virg. En. 7.312), que é literalmente traduzido por Tassilo Orpheu Spalding - 'Se não posso dobrar os deuses do Olimpo, revolverei o Aqueronte!'45 - e muito concisamente por Odorico Mendes - 'Vou, se não movo o céu, mover o inferno' ${ }^{46}$.

Isso, a Juno virgiliana. Sob a pena de Sílio Itálico, Juno dá a Tisífone a tarefa de fazer cair Sagunto. Observamos, antes, que Juno é a deusa cruel, seva, na Eneida; a deusa perturbada, nas Púnicas. Pois olhemos agora aos versos 543 e 544. O adjetivo virgiliano de descrição da deusa Juno, saeua, aparece aqui, em Sílio Itálico, atribuído a Tisífone. Sílio descreve a Fúria como Juno é descrita na Eneida. É como se a Tisífone siliana fosse uma continuação da Juno virgiliana; a característica mais marcante

\footnotetext{
${ }^{43}$ Spaltenstein, p. 160.

${ }^{44}$ Para uma descrição siliana do rio, veja-se o que ficou dito na nota 31.

${ }^{45}$ Virgílio, 1981, p. 142.

${ }^{46}$ Virgílio, Eneida brasileira, trad. Manuel Odorico Mendes, org. Paulo Sérgio de Vasconcellos et alii. Campinas/SP, Editora da Unicamp, 2008, p. 287.
} 
que a Juno virgiliana tem atribuída a si mesma, Sílio a atribui à Fúria, que é, por conseguinte, identificada com Juno.

Em suma, o que temos aqui é uma espécie de transferência da ira e da crueldade da deusa que ordena à sua subordinada, a Fúria, que, aliás, nos mesmos versos 543 e 544, ao lado de 'seva', 'cruel', saeua, é denominada 'Eumênide', 'a benfazeja', o epíteto positivo ao lado de um adjetivo negativo. Essa antítese que coteja bem e mal, bondade e crueldade, lembra-nos que a deusa Juno, boa, olímpica, é também cruel, como a deusa Tisífone, má, infernal. E se o sacrifício opera por meio da substituição e da troca, como vimos, com a própria vítima tendo um valor que é simbólico, substituindo quem a oferece, a transferência aqui não é diferente: trata-se de uma substituição, de uma troca, que mescla elementos próprios da caracterização da deusa Juno na configuração da deusa Tisífone, 'o colapso de distinções que resulta do jogo dos modelos literários ${ }^{947}$.

Como conclusão, é essa confusão entre 'Paraíso e Inferno', para usar mais uma expressão de Hardie ${ }^{48}$, essa 'mescla', que vemos na sinestesia, na ideia recorrente de circunferência, na sintaxe mimética e nos outros tantos elementos apontados, é que constrói a figura de Tisífone em Sílio Itálico, uma deusa infernal que se confunde com a sua mandante paradisíaca, Juno, elaborando, por fim, elementos da Eneida de Virgílio numa releitura muito própria, pois 'as Púnicas de Sílio Itálico são a continuação histórica da Eneida [...]. Sob tais condições, a imitação, em vez de ser mera técnica literária, torna-se uma obrigação'49.

\section{Trtce. Silius Italicus' Tisiphone: Punica 2.526-52.}

AвSTRACт. This paper focuses on Tisiphone's first appearance in Silius Italicus' Punica (2.526-52) and considers the depiction of the infernal deity. It inserts Silius in his productive period and, by analysing the text in hand, traces the way Tisiphone's followers, the geographical alterations caused by her presence and her doings serve as characterising instruments in those lines, besides examining her description presented both in the poet's words and Juno's. Finally, this paper investigates the relation between the Fury and her Olympian sender, Juno, and argues that Silius' Tisiphone is the result of a dialogue with Virgil's Juno in the Aeneid.

Keywords. Tisiphone; description; Silius Italicus; Juno; Virgil's Aeneid.

\footnotetext{
${ }^{47}$ P. Hardie, p. 34.

${ }^{48}$ Hardie intitulou assim seu capítulo 3: 'Heaven and Hell'.

${ }^{49}$ Michael von Albrecht, Roman Epic: an interpretative introduction. Leiden, Boston, Köln, Brill, 1999, p. 294.
} 